\title{
AMOR, ÉTICA Y JUSTICIA
}

\author{
CARLOS GÓMEZ SÁNCHEZ \\ UNED (Madrid)
}

\begin{abstract}
RESUMEN: Se trata de examinar las relaciones entre amor, ética y justicia, adoptando cuatro perspectivas complementarias: en primer lugar, se aborda la confrontación con Freud, en su enconada diatriba contra el concepto de «amor al prójimo». En segundo lugar, se plantea la confrontación con Kant, bajo la forma de la disputa entre «amor» e «imperativo». Situados así en el terreno de la ética, se consideran (3) las relaciones entre amor y justicia, sirviéndonos ante todo de los análisis de Ricoeur, para abordar finalmente (4) lo que podríamos denominar "el amor a los fuera de la ley», apoyándonos en algunos personajes literarios de Dostoievski.
\end{abstract}

PALABRAS CLAVE: amor; ética; justicia; Freud; Kant; Ricoeur; Dostoievski.

\section{Love, Ethics, and Justice}

ABSTRACT: This text will examine the relations between love, ethics, and justice, adopting four complementary perspectives. The first is the confrontation with Freud, in his ardent diatribe against the concept of «loving your fellow man». Then, the confrontation with Kant is presented, in the form of the dispute between «love» and «imperative». Having situated the issue, thus, in the terrain of ethics, the relations between love and justice are considered, using mainly Ricoeur's analysis. Finally, what could be called "love of outlaws» will be dealt with, through some of Dostoievski's literary characters.

KEY WORDS: love; ethics; justice; Freud; Kant; Ricoeur; Dostoievski.

El amor es un tema mayor, inmenso, en el que es fácil oscilar entre la exaltación o el sentimentalismo, cuando no desembocar en la negación cínica. Dada la dificultad de abordarlo derecha y centralmente, adoptaremos respecto al mismo la que podríamos denominar «táctica de Josué», esto es, circunvalarlo, como Josué rodeó las murallas de Jericó al son de trompetas dramáticas, hasta que se derrumbaron. Nuestro cuestionamiento no será tan dramático — pese a no estar exento de tensiones - ni esperamos que la fortificación se nos rinda por completo, sino únicamente que nos ofrezca algunos de sus flancos, para que ese análisis pueda más tarde enlazar con otros aspectos o flancos de la cuestión.

Para ello adoptaremos cuatro perspectivas complementarias. En primer lugar, examinaremos uno de los ataques más fuertes que al concepto de amor, entendido como "amor al prójimo», se han llevado a cabo: el de Freud en la diatriba que con él mantiene en el capítulo V de El malestar en la cultura. Tras la confrontación con Freud vendrá la confrontación con Kant, bajo la forma de la disputa entre "amor» e "imperativo», tomando como base tanto la Fundamentación para una metafísica de las costumbres, como algunos pasajes pertinentes de la Crítica de la razón práctica. Situados así en el terreno de la ética, nos encaminaremos a considerar las relaciones entre amor y justicia, virtud principal con sus dos vertientes individual y social, para ver qué puede agregar el amor, si es que algo agrega, a la justicia y cómo quizá necesite con todo apoyarse en ella, para lo que nos serviremos ante todo del análisis que de 
la «regla de oro» realizó Ricoeur en algunos de los ensayos de su obra Amor y justicia, mas atendiendo asimismo a algunos otros textos. Finalmente, querría considerar lo que podríamos englobar bajo la rúbrica de «el amor a los fuera de la ley», para lo que me apoyaré ante todo en algunos personajes de Dostoievski, y principalmente en Marmeladov, de Crimen y castigo.

\section{LA CRÍTICA AL «AMOR AL PRÓJIMO» (LA POLÉMiCA CON FREUd)}

Por qué el amor sea mejor que el odio es difícil de fundamentar, como destacan varios de los autores a los que recurre Alfred A. Häsler en su obra El odio en el mundo actual ${ }^{1}$ y como yo mismo, entre otros, tuve ocasión de analizar en el volumen sobre el odio editado por Carlos Castilla del Pino². Quizá porque, como indicó Wittgenstein en Sobre la certeza, aquello que fundamenta no puede acabar de ser a su vez fundamentado ${ }^{3}$. En todo caso, el amor juega un papel central no sólo en las relaciones personales y sociales sino en la propia filosofía, como sabemos al menos desde El Banquete platónico, al que apela Ortega cuando en los albores de su filosofía, en la obra que contiene in nuce muchos de sus temas posteriores, esto es, en Meditaciones del Quijote, quiere hacer del amor el eje central sobre el que gire el universo, habiendo de entender esos ensayos, nos advierte, resucitando el lindo nombre que le dio Spinoza, como «ensayos de amor intelectual». Ortega, quizá el Ortega más entusiasta y animoso, quería llevar ahí todas las cosas «—un hombre, un libro, un cuadro, un paisaje, un error, un dolor- a la plenitud de su significado. Colocar las materias de todo orden, que la vida, en su resaca perenne, arroja a nuestros pies como restos inhábiles de un naufragio, en postura tal que dé en ellas el sol innumerables reverberaciones». Y esto es el amor, nos dice, «el amor a la perfección de lo amado» ${ }^{4}$, a diferencia del odio que, a su entender, se había atrincherado en el alma de los españoles «moviendo guerra» al mundo y suprimiendo pedazos enteros de lo real.

Pero, lo pudiéramos entender así o no, y por hermoso que nos pueda parecer, lo cierto es que el concepto de amor ha recibido también críticas muy severas. Y para no referirme a otras (como la realizada entre nosotros por Fernando Savater en su Ética como amor propio ${ }^{5}$, a la que en alguna ocasión me he referido para sopesarla críticamente, incluyendo en esa ponderación a Ética y psicoanálisis de Fromm ${ }^{6}$, en el que en efecto el propio Savater en buena

\footnotetext{
1 Häsler, A., El odio en el mundo actual, trad. de F. Latorre, Alianza, Madrid, 1973.

2 Castilla del Pino, C., El odio, Alianza, Madrid, 2002.

3 Wittgenstein, L., Sobre la certeza, trad. de J. L. Prades y V. Raga, Gedisa, Barcelona, 1987.

4 Ortega y Gasset, J., Meditaciones del Quijote, en Obras completas, Revista de Occidente, Madrid, T. I, $7^{\text {a }}$ ed., 1966, p. 311.

5 Savater, F., Ética como amor propio, Ariel, Barcelona, 2008.

6 Fromm, E., Ética y psicoanálisis, trad. de H. F. Morck, FCE, México, 1953.
} 
medida se basa ${ }^{7}$ ), me centraré en la enconada diatriba que en el capítulo $\mathrm{V}$ de El malestar en la cultura Freud realiza al concepto de "amor al prójimo», tratando de hacer ver cómo, a pesar de ella, Freud acabará defendiendo su necesidad social.

Es cierto que, sin apelar a la noción de pulsión de muerte, autores anteriores a Freud ya habían sido muy críticos con una imagen edulcorada del hombre, que lo idealizaría de modo equívoco. Por ejemplificarlo brevemente en Kant, del que nos ocuparemos más tarde en la confrontación entre amor e imperativo. Para él, tal como lo formula en La religión dentro de los límites de la mera razón, podríamos ahorrarnos la prueba protocolaria de la propensión corrupta «en vista de la multitud de estridentes ejemplos que la experiencia nos pone ante los ojos en los actos de los hombres». Y, en una clara alusión a Rousseau, agrega que si los queremos obtener «de aquel estado en el que algunos filósofos esperaban encontrar de modo excelente la bondad natural de la naturaleza humana, a saber, del llamado estado de naturaleza», pueden compararse con esa hipótesis las escenas de crueldad no provocada en repetidas ceremonias sangrientas de pueblos primitivos, de las que ni siquiera hombre alguno obtiene la menor ventaja. Pero si uno se ha decidido por la opinión de que la naturaleza humana se deja conocer mejor en el estado civilizado (en el que sus disposiciones pueden desarrollarse de un modo más completo), entonces:

«Habrá que oír una larga letanía melancólica de acusaciones a la humanidad; acusaciones de secreta falsedad, incluso en la amistad más íntima, de modo que la moderación de la confianza en las revelaciones recíprocas, incluso de los mejores amigos, es contada como máxima general de prudencia en el trato; de una propensión a odiar a aquél a quien se está obligado, para lo cual ha de estar siempre preparado el bienhechor; de una benevolencia cordial que, sin embargo, permite observar que "hay en la desdicha de nuestros amigos algo que no nos desagrada del todo", y de muchos otros vicios escondidos bajo la apariencia de virtud $»^{8}$.

Todo ello por no hablar de las relaciones exteriores entre los pueblos, que aún están en el rudo estado de naturaleza (asociado aquí, hobbesianamente, a la constante disposición hacia la guerra), lo que hace del quiliasmo filosófico un objeto de burla o fanatismo 9 .

Con todo, aunque Kant no deja de insistir en el capítulo primero de esa obra, y tal como lo titula, en «el mal radical en la naturaleza humana», tal inclinación al mal es una propensión, inextirpable, sí, pero menos fuerte que una más firme disposición hacia el bien, en la que podrá basar los postulados de Dios y la inmortalidad, como había hecho ya en su anterior Crítica de la razón práctica. Postulación, pues, y frente a algunas lecturas, que no se hace en función del

7 Gómez, C., «Defensa de la compasión en contra de sus entusiastas», Sistema, 139 (1997), pp. 45-65.

8 Kant, I., La religión dentro de los límites de la mera razón, ed. de F. Martínez Marzoa, $2^{a}$ ed., Alianza, Madrid, 1981, p. 43.

9 Ibid., p. 44. 
mal ni como simple compensación al mismo, pues de la podredumbre humana difícilmente puede trazarse una vía, ni siquiera postulatoria, que nos lleve al Gran Doctor, sino a pesar del mal, esto es, basándose en las tendencias morales también presentes entre los hombres, que a veces incluso, dice el sobrio Kant y pese al recelo que en él despertaba toda exaltación, todo lo schwärmerish, llegan a provocar nuestro entusiasmo ${ }^{10}$.

En esas condiciones, si es que la naturaleza persigue fines, observará en la Fundamentación para una metafísica de las costumbres, no parece que entre esos fines se encuentre la felicidad humana, pues entonces mejor sería que la naturaleza hubiera dotado al hombre con un sistema de instintos que le acloparan básicamente al medio, mientras que, al dotarle de libertad y razón, parecería que se ha comportado como una mala madrastra, dado que en su uso el hombre se extravía incluso respecto a lo deseado, lo que lleva a muchos a una cierta misología u odio a la razón. Mas, tal vez, propone Kant, se trate de que nuestro fin no sea tan sólo alcanzar la felicidad que anhelamos, sino, a través de nuestra tarea moral posibilitada por la libertad, hacernos dignos de esa felicidad a la que aspiramos ${ }^{11}$.

Como si hiciera eco a esas observaciones, pero dando una vuelta de tuerca, el irreligioso Freud, para dirigirnos ya a él, comentará en el capítulo 2 de $E l$ malestar en la cultura, que todo el orden del universo parece oponerse a un duradero estado de placer para el hombre, «y aun estaríamos por afirmar - subraya irónicamente- que el plan de la "Creación" no incluye el propósito de que el hombre sea "feliz" $»^{12}$. Como se sabe, el propósito de la obra es un

10 KANT, I., Si el género humano se halla en progreso constante hacia mejor, en Filosofía de la Historia, trad. de E. Ímaz, $4^{a}$ reimp., FCE, México, 1985, pp. 95-118. Quizá el pasaje más significativo, referido a la Revolución Francesa, dice así: «Esta revolución de un pueblo lleno de espíritu, que estamos presenciando en nuestros días, puede triunfar o fracasar, puede acumular tal cantidad de miseria y de crueldad que un hombre honrado, si tuviera la posibilidad de llevarla a cabo una segunda vez con éxito, jamás se decidiría a repetir un experimento tan costoso. Y, sin embargo, esta revolución encuentra en el ánimo de todos los espectadores, que no están complicados en el juego, una participación de su deseo, rayana en el entusiasmo, cuya manifestación, que lleva aparejada un riesgo, no puede reconocer otra causa que una disposición moral del género humano» (Ibid., pp. 105-106)

11 Kant, I., Fundamentación para una metafísica de las costumbres, ed. de R. Rodríguez Aramayo, Alianza, Madrid, 2002, pp. 65-66 (A4-A5).

12 Freud, S., El malestar en la cultura, en Obras completas, trad. de L. López-Ballesteros y de Torres, $3^{\text {a }}$ ed., Biblioteca Nueva, Madrid, 1973, 3 vols., T. III, p. 3025. (La traducción de López-Ballesteros incurre en el error de traducir indistintamente Instinkt (instinto) y Trieb (pulsión) por instinto, lo que tergiversa la argumentación freudiana de muchos pasajes, error que se repite en la afamada Standard Edition, pero que se ha corregido en la más reciente traducción al castellano llevada a cabo por J. L. Etcheverry en Amorrortu. Con todo, teniéndolo en cuenta y subsanándolo cuando sea preciso, prefiero seguir la de LópezBallesteros, que, a mi entender, gana mucho en riqueza literaria, lo que en un autor como Freud, premio Goethe, no es menor. En cualquier caso, en la edición de El malestar en la cultura que preparé para Alianza revisé, como ahí advierto, la traducción y ni una sola vez Freud utiliza en el texto el término Instinkt, siempre Trieb y sus derivados. Cf. Freud, S., El malestar en la cultura y otros ensayos, introd. de C. Gómez, Alianza, Madrid, $3^{\mathrm{a}}$ ed., $3^{\mathrm{a}}$ reimpr., 
nuevo intento de estudiar las tensas relaciones entre el individuo y la cultura, tema en Freud de larga data, al que el estudio de 1930 aportará, sin embargo, novedades significativas. Si la tarea general de la cultura es hacer frente a la supremacía de la naturaleza y regular las relaciones sociales entre los hombres a través de los lazos libidinales entre ellos, esto es, lo que se podría resumir en el programa de Ananké y Eros, lo sorprendente es que las instituciones sociales, fruto del ser humano, no logren un resultado satisfactorio e incluso desemboquen necesariamente — será la tesis fundamental del estudio- en una tensión ineludiblemente trágica. Y ahí es donde inserta su consideración respecto al mandamiento cristiano de «amar al prójimo» que le parece el principio moral más exigente que hasta ahora se ha formulado, pues no se contenta, como la Regla de Oro, con exigir no hacer al otro lo que uno no quiere para sí, sino que manda positivamente amar al otro, mandamiento en el que se incluye, como observa bien, la desmesura incluso de «amar al enemigo». $\mathrm{Y}$ es este precepto, que le parece en principio absurdo, el que va a ser blanco de sus críticas en el capítulo $5^{\circ}$ de la obra, hasta el momento más o menos serena, pero que a partir de entonces adopta un giro mucho más agrio.

La diatriba freudiana se puede descomponer, en realidad, en dos argumentos sucesivos. Considero que el primero de ellos es meramente retórico, en el sentido habitual y peyorativo de la expresión ${ }^{13}$. El amor general por todo el Universo y por todos los seres humanos, no sólo le parece muy difícil de cumplir, sino además desaconsejable e injusto, pues los cercanos aprecian el amor como una muestra de preferencia, que desaparecería si se los equiparase con ajenos y extraños:

«[Alguien] merecería mi amor si se me asemejara en aspectos importantes, a punto tal que pudiera amar en él a mí mismo; lo merecería si fuera más perfecto de lo que soy yo, en tal medida que pudiera amar en él al ideal de mi propia persona; debería amarlo si fuera el hijo de mi amigo, pues el dolor de éste, si algún mal le sucediera, también sería mi dolor, yo tendría que compartirlo. En cambio, si me fuera extraño y no me atrajese ninguno de sus propios valores, ninguna importancia que hubiera adquirido para mi vida afectiva, entonces me sería muy difícil amarlo. Hasta sería injusto si lo amara, pues los míos aprecian mi amor como una demostración de preferencia, y les haría injusticia si los equiparase con un extraño» ${ }^{14}$.

Es obvio, sin embargo, que solemos amar preferentemente a los que nos son más cercanos, familiares, amigos, compatriotas, y es lógico e incluso

2010. Un estudio de conjunto de la obra de Freud, lo llevé a cabo en Gómez, C., Freud y su obra. Génesis y constitución de la Teoría Psicoanalitica, Biblioteca Nueva-Asociación Psicoanalítica de Madrid, Madrid, 2002, $3^{\text {a }}$ ed., 2014).

13 Para otros sentidos del término convendría cf. Ch. Perelman, Tratado de la Argumentación. La Nueva Retórica, Madrid, Gredos, 1989; El Imperio retórico: Retórica y argumentación, Norma, Bogotá, 1997. También, entre nosotros, V. Camps se ocupó de la cuestión en Ética, retórica, política, Alianza, Madrid, 1988.

14 Freud, S., El malestar en la cultura, en O. C., cit., T. III, p. 3044 
debido que sea así, pues en muchos casos dependen de nosotros y nadie quizá se ocuparía de ellos si nosotros no lo hiciésemos. Pero a lo que se opone el mandamiento cristiano es a que ese amor por los cercanos llegue a conculcar deberes que tenemos respecto a todos los demás, por lejanos y ajenos que en primera instancia nos resulten, y previene respecto a la facilidad con la que ese amor preferencial degenera en formas de corrupción y nepotismo, favoreciendo a los conocidos frente a los justos méritos presentados por otros, si es que no en conductas más o menos mafiosas, solidarizándonos sólo, como en la película de Martin Scorsese, con Uno de los nuestros. Que el propio Freud tendía a ver las cosas así, pese a su encendido alegato, lo prueba el que poco después desarrolle el concepto de «narcisismo de las pequeñas diferencias» ${ }^{15}$, para expresar la satisfacción de la agresividad contra un grupo, más o menos cercano, pero considerado extraño, fortaleciendo de este modo la cohesión entre los miembros de la comunidad. Y, entre otros ejemplos, Freud no puede dejar de recordar la secular persecución de los judíos en las sociedades cristianas.

Pasando, pues, a una segunda línea crítica, Freud destaca la agresividad inherente a cada individuo, que convierte a cada uno de ellos en potencial agresor, merecedor antes de odio que de amor. El hombre no es una criatura tierna y necesitada de amor, que sólo osaría defenderse si se le atacara, sino, por el contrario, un ser entre cuyas disposiciones pulsionales también debe incluirse una buena porción de agresividad. Y la exposición freudiana recuerda, e incluso incrementa, alguno de los sombríos tintes que vimos en la de Kant, por cuanto la mera experiencia de sentirse superior puede desencadenar los más feroces ataques:

«Siempre que le sea de alguna utilidad, no vacilará en perjudicarme, y ni siquiera se preguntará si la cuantía de su provecho corresponde a la magnitud del perjuicio que me ocasiona. Más aún: ni siquiera es necesario que de ello derive un provecho; le bastará experimentar el menor placer para que no tenga escrúpulo alguno en denigrarme, en ofenderme, en difamarme, en exhibir su poderío sobre mi persona, y cuanto más seguro se sienta, cuanto más inerme me encuentre yo, tanto más probablemente puedo esperar de él esta actitud para conmigo [...]. Por consiguiente, el prójimo no le representa únicamente un posible colaborador y objeto sexual, sino también un motivo de tentación para satisfacer en él su agresividad, para explotar su capacidad de trabajo sin retribuirla, para aprovecharlo sexualmente sin su consentimiento, para apoderarse de sus bienes, para humillarlo, para ocasionarle sufrimientos, martirizarlo y matarlo» ${ }^{16}$.

Sin considerar la crítica económica del sistema comunista, que, dice, no le concierne, no puede dejar de destacar como vana ilusión su hipótesis psicológica, pues aunque es cierto que al abolir la propiedad privada se sustrae a la agresividad humana uno de sus instrumentos, sin duda uno muy fuerte, la agresividad no es una mera consecuencia de ella y tiene raíces pulsionales

$15 \quad$ Ibid., p. 3048.

16 Ibid., pp. 3045-3046. 
más hondas. Se trata de la pulsión de muerte, manifiesta en el escenario de la cultura como violencia y guerra, que amenaza la sociedad civilizada y la pone "constantemente al borde de la desintegración» ${ }^{17}$.

Y este es el sentido del mandamiento de amar al prójimo, pese a que la pendiente de la argumentación freudiana parecía desacreditarlo. Más bien, dicha argumentación viene a resaltar, frente a imágenes idealizadas del ser humano, su inmensa dificultad, como quiso subrayar asimismo Lacan en La ética del psicoanálisis ${ }^{18}$. Pero su tarea es irrenunciable. El «malestar» (Unbehagen) en la cultura del que Freud habla en la obra de 1930 no se expresa ante todo como conflicto entre pretensiones individuales y coacción social, sino como conflicto pulsional que atraviesa, a la vez, a los individuos y a las instituciones culturales. Para que éstas se mantengan, las pulsiones eróticas, que amalgaman a unos individuos y grupos con otros, han de florecer; mas, para ello, es preciso limitar las tendencias agresivas (ese es el sentido del mandamiento) y la cultura no ha encontrado mejor recurso que devolver contra el individuo la agresividad que él de buena gana dispensaría a otros, haciéndole vigilar por una instancia alojada en su interior "como guarnición militar en ciudad conquistada $»^{19}$, dice Freud recurriendo al registro metafórico militar — quizá su preferido, junto al arqueológico-. Es la tarea del superyó. De ahí una exaltación del sentimiento de culpabilidad, sentimiento que resulta ineliminable y «el problema más importante de toda la evolución cultural» ${ }^{20}$.

Denostando los prejuicios entusiastas de la Ilustración, sin renunciar por completo a sus ideales, sino enraizándolos y contextualizándolos para que no nos lleven a fáciles espejismos, esto es, tratando de ilustrar a la Ilustración misma, Freud parece apuntar a lo trágico de la cultura, de la que no nos podemos desembarazar, pero en la que no acabamos de podernos desenvolver. Visión sombría que, como apunta Habermas, no excluye, sin embargo, la perspectiva crítico-revolucionaria, sino que, «al contario, tiene la ventaja de excluir la certeza totalitaria» ${ }^{21}$.

Mas dejando esas implicaciones para lo que cabría llamar Filosofía de la Historia, quedémonos con que, pese a la dificultad de su fundamentación, el amor, en cuanto amor al prójimo, ha resistido uno de los embates más intensos llevados a cabo y precisamente por un autor declaradamente antirreligioso y anticristiano, como Freud sin duda lo fue. Quizá el concepto nos revele otras perspectivas si en vez de preguntarnos por su sentido cultural, lo confrontamos con el de deber, tal como se ofrece en la formulación kantiana.

\footnotetext{
17 Ibid., p. 3046.

18 Lacan, J., La ética del psicoanálisis, El seminario, vol. 7, texto establecido por J.-A. Miller, trad. de D. S. Rabinovich, Paidós, Barcelona, 1988.

19 Freud, S., El malestar en la cultura, cit., p. 3053.

$20 \quad$ Ibid., p. 3060

21 Habermas, J., Conocimiento e interés, trad. de M. Jiménez, J. F. Ivars y L. Martín Santos, Taurus, Madrid, 1982, p. 280
} 


\section{AMOR E IMPERATIVO. LA CONFRONTACIÓN CON KANT}

El problema sobre el que querría ahora llamar la atención, a propósito de las relaciones entre amor e imperativo en la ética kantiana, deriva de la clasificación de las acciones respecto al deber llevada a cabo por Kant. Como se sabe, aquellas fueron clasificadas como contrarias al deber (que indudablemente son inmorales), conformes al deber, pero no por deber (que tampoco alcanzan el grado de moralidad) y conformes al deber y por deber, que son las únicas que pueden ser consideradas morales ${ }^{22}$. Ahora bien, las clasificaciones no son ni verdaderas ni falsas, sino que intentan adentrarnos en un nudo de problemas y, en ese sentido, podemos considerarlas más bien como relevantes o confundentes (cuando destacan rasgos no significativos y de ese modo nos extravían o cuando engloban en un mismo tipo caracteres o individuos que habrían de diferenciarse). Y la clasificación kantiana, que desde luego no me parece irrelevante, sí podría resultar, sin embargo, un tanto confundente, al incluir, dentro del registro de lo realizado conforme al deber, pero no por deber, acciones de muy diferente condición. Es cierto que el ejemplo kantiano resulta bastante inapelable. Kant se refiere al comerciante que vende a un precio justo, pero no por cumplir con una adecuada regulación y menos aún por respeto al cliente, sino porque de ese modo espera poder vender más, de modo que su acción, aun siendo conforme con el deber, carece de valor moral al ir guiada por el propio interés de obtener mayor beneficio. El problema es que, dentro de las acciones realizadas por interés (a diferencia de las acciones morales en las que tomamos interés), cabe registrar actitudes muy diferentes, desde el crudo afán de ventajas materiales del ejemplo kantiano a otras más cercanas al afecto positivo e incluso el amor, sin que parezca adecuado incluirlas en el mismo saco, o en el mismo registro, haciéndolas caer a todas ellas en el ámbito de los intereses patológicos. Y, por tanto, parece que la clasificación kantiana requeriría de un cuarto elemento, que sería el de aquellas acciones conformes al deber, pero no por deber, mas no obstante no guiadas por interés patológico alguno, sino al contrario por inclinación afectiva o amorosa, capaz no sólo de respeto, sino de desprendimiento hacia el otro y generosidad.

La cuestión la puso bien, e irónicamente, de relieve Schiller en unos célebres versos. En efecto, en su conocido epigrama Los escrúpulos de conciencia, Schiller se burlaba del rigorismo kantiano, al señalar:

«Yo ayudo con gusto a los amigos, pero desgraciadamente lo hago por mor de la inclinación, y a menudo me aflige el hecho de no ser virtuoso. No queda otro remedio: intentaré despreciarlos y obrar entonces, como demanda el deber, con aversión ${ }^{23}$.

${ }^{22}$ Kant, I., Fundamentación para una metafísica de las costumbres, cit., pp. 69-71 (A8-A11)

${ }_{23}$ Cit. en Schopenhauer, A., Metafísica de las costumbres, ed. de R. Rodríguez Aramayo, Debate/CSIC, Madrid, 1993, p. 154. 
En qué sentido y hasta qué punto ha de tomarse la parodia de Schiller ha sido discutido ampliamente por los kantólogos ${ }^{24}$. Para nuestros efectos, bástenos decir que el sentir común apreciará indudablemente más a alguien que nos ama, que a alguien que simplemente cumple sus deberes hacia nosotros. Es cierto, en cualquier caso, que el amor no puede mandarse. Y, en este sentido, el precepto cristiano ha de entenderse como formulado a la manera legal y usual de hablar, como un mandato o como una ley, para negarla y superarla, sin por eso conculcarla ${ }^{25}$. Se trataría, a través de la educación, de intentar que amemos y disfrutemos con lo que nos parezca debido, o, según trataba de fomentar la ética aristotélica, de introducir el logos en el pathos a través del êthos, pues, como el propio Aristóteles advierte, el criterio para saber si se ha adquirido una virtud es si se disfruta con ella ${ }^{26}$. En este sentido, el amor parece superior al mero cumplimiento del deber. Como advirtiera Ortega cuando trataba de hacer la crítica de Kant: «El deber es cosa importante pero secundaria —es el sustituto, el Ersatz de la ilusión. Es preciso que hagamos, siquiera por deber, lo que no logramos hacer por ilusión» ${ }^{27}$.

Con todo, eso no resta grandeza a la moral del deber, puesto que no siempre podemos amar lo que debemos, que es por lo que cumplir acciones que consideramos debidas pero que no deseamos tiene mérito moral. Es decir, que aun concediendo la superioridad del amor (siempre en referencia al deber para no extraviarse en mero sentimentalismo que lo conculca), creo que se tergiversaría lo que es la vida moral si se prescindiera del básico componente de renuncia que tiene y que, quizá por eso, hace de ella algo no siempre

24 Cf., entre otros, y tras la clásica obra de Paton (РAton, H. J., The Categorical Imperative: a Study in Kant's Moral Philosophy, University of Chicago Press, Chicago, 1948), la de Allison, H. E., Kant's Theory of Freedom, Cambridge University Press, Cambridge, 1990, o la de Beiser, F., Schiller as Philosopher. A Re-examination, Clarendon Press, Oxford, 2005. Entre nosotros, para esa y otras cuestiones conexas, serán de utilidad Muguerza, J., y Rodríguez Aramayo, R., Kant después de Kant, Tecnos, Madrid, 1989, el excelente volumen de Gómez Caffarena, J., El teísmo moral de Kant, Cristiandad, Madrid,1983, así como los estudios de Rivera de Rosales, J., "La moralidad. Hegel versus Kant. I», en M. Álvarez Gómez y M. C. Paredes Martín, La controversia de Hegel con Kant, Universidad de Salamanca, Salamanca, 2004, y "La moralidad. Hegel versus Kant. II», Éndoxa, 18 (2004), pp. 383-416. Desde el punto de vista del papel de las emociones en la moral, y desde una perspectiva básicamente no kantiana, cf. CAmps, V., El gobierno de las emociones, Herder, Barcelona, 2011. (Realicé un comentario a esta obra en Gómez, C., "Razones y emociones», Isegoría, 45 (2011), pp. 765770).

25 Gómez, C., «Ética y religión», en C. Gómez y J. Muguerza (eds.), La aventura de la moralidad. Paradigmas, fronteras y problemas de la Ética, Alianza, Madrid, 2007, pp. 278-329 (hay reimpresiones posteriores). Entre otros, tres estudios del ya citado Gómez CAFFARENA serían asimismo de interés al respecto: «El cristianismo y la filosofía moral cristiana», en V. CAmps, Historia de la Ética, I, Crítica, Barcelona, 1987, pp. 282-344; Qué aporta el cristianismo a la ética, Fundación Santa María, Madrid, 1991; «Religión y ética. Quintas Conferencias Aranguren», Isegoría, 15 (1997), pp. 227-269.

26 Aristóteles, Ética nicomáquea, introd. de E. Lledó, trad. de J. Pallí, Gredos, Madrid, 1985, Libro II, cap. 3, pp. 162-164, 1104b-1105a

27 Ortega y Gasset, J., ¿Qué es filosofía?, en O. C., cit., T. VII, p. 426. 
divertido, como deploraba Nietzsche al indicar que todos los moralistas son aburridos. Mas, con independencia de lo arbitrario de esa apreciación —no creo que el aburrimiento sea la nota predominante de Sócrates, por ejemplo-, hay en ella algo que se debe registrar, solo que más que para deplorarlo, para hacerse cargo. Y es que la moral conlleva, al menos en parte, un gesto severo, de renuncia. Como Freud supo desde muy pronto, y así lo anuncia ya en su Proyecto de una psicología para neurólogos, de 1895, la educación requiere displacer ${ }^{28}$. Quizá porque, por decirlo ahora al modo kantiano, nuestra voluntad puede ser buena, pero no santa, que es por lo que cumplir el deber que nos disgusta tiene valor moral. Una voluntad santa sería aquella en la que lo debido y lo querido siempre coincidiesen y tal voluntad no requeriría de coacción ni, por tanto, de imperativos. Pero, por idealizada que sea nuestra imagen, no es preciso ir muy lejos ni aducir muchos ejemplos para saber que no es el caso.

De este modo, el mérito moral del que hablamos al cumplir el deber que nos disgusta, es también un índice apuntando a nuestra imperfecta disposición, pues mejor sería que lo debido nos gustara y nos ilusionara - como a veces, en efecto, sucede. Pero hasta que esa situación llegue a ser habitual, esto es, hasta que se realice, si es que alguna vez se realiza, tamaña conversión, semejante transformación a fondo de nuestros deseos (transformación que nunca se puede dar por asegurada, por perfectamente cumplida, pues en la vida moral, y por elevada que sea la cima a la que uno se haya podido encaramar, la regresión al inmoralismo es siempre una desgraciada posibilidad con la que hay que contar), el deber no dejará de comportar un rasgo inevitable, qué le vamos a hacer, de constricción.

Kant fue consciente de esta dura dialéctica de amor y deber. Y aunque, según hemos tratado de hacer ver, no sigamos sus formulaciones en todo su recorrido, ello no quiere decir que no se hiciera cargo de la cuestión, como lo manifiestan, por ejemplo, los siguientes pasajes de su Crítica de la razón práctica, con los que concluiremos esta sección:

"Amar al prójimo" quiere decir "ejercer de buena gana cualquier deber para con él". Mas el mandato que hace de esto una regla tampoco puede ordenar el tener esa intención en las acciones conformes al deber, sino simplemente tender hacia ello. Pues un mandato relativo a que se deba hacer algo de buena gana es contradictorio, porque cuando ya sabemos por nosotros mismos lo que nos incumbe hacer, si además fuéramos también conscientes de que nos gusta hacerlo, un mandato relativo a ello sería enteramente superfluo y si no lo hacemos precisamente de buena gana, sino tan sólo por respeto hacia la ley, entonces un mandato que convierta ese respeto en móvil de una máxima estaría justamente atentando contra la intención ordenada. Esa ley de leyes presenta por lo tanto, al igual que cualquier precepto moral del Evangelio, la intención moral en su plena perfección tal como, en cuanto un ideal de santidad, es inalcanzable por ninguna criatura, constituyendo sin embargo

28 Freud, S., Proyecto de una psicología para neurólogos, en O. C., cit., T. I, p. 264. 
el arquetipo al que debemos tender a aproximarnos e igualarnos en un progreso ininterrumpido pero infinito. Si una criatura racional pudiese llegar alguna vez a ejecutar completamente todas las leyes morales de buena gana, esto significaría tanto como no hallar nunca en ella ni siquiera la posibilidad de un deseo que le incitase a desviarse de las mismas; pues el sobreponerse a semejante deseo siempre le cuesta un sacrificio al sujeto, precisando pues de autoconstricción, o sea, de un apremio interno hacia lo que no se hace totalmente de buena gana. Pero a este grado de intención moral jamás puede llegar una criatura" 29 .

\section{AMOR Y JUSTICIA}

De Aristóteles a Rawls, la justicia se refiere a una métrica que trata de dar a cada uno lo suyo. Uno de los principios más antiguos que intenta formularla es la conocida como Regla de Oro, lentamente impuesta en la historia de la humanidad, según ha destacado Karem Armstrong en La gran transformación, siguiendo la inspiración de lo que Karl Jaspers llamó el tiempo-eje ${ }^{30}$. Pero esa regla, en la cuidada interpretación de Ricoeur ${ }^{31}$, puede entenderse en el sentido de un mero cálculo utilitarista ( "no te daño para que no me dañes"), que nos llevaría a variaciones sobre la Ley del Talión, esto es, desde una lógica de la equivalencia, o desde una lógica de la sobreabundancia, que quisiera introducir el amor más allá de la reciprocidad, es decir, no hacer al otro lo que no quisiéramos para nosotros, aunque el otro nos lo hiciera.

Esa regla de oro que, según algunos intérpretes, también se encuentra filosóficamente traspuesta en las diversas formulaciones que Kant dio del imperativo categórico, y quizá ante todo en la primera de ellas, probablemente ha alcanzado su mayor nivel de formalización en el segundo principio de la justicia de John Rawls ${ }^{32}$ : maximizar la parte mínima, dado que, tras el velo de

29 Kant, I., Crítica de la razón práctica, ed. de R. Rodríguez Aramayo, Alianza, Madrid, 2000, pp. 177-178, A148-A149.

30 Armstrong, K., La gran transformación. El origen de las tradiciones religiosas, trad. de A. Herrera, Paidós, Barcelona, 2007.

31 Ricoevr, P., Amor y justicia, trad. de T. Domingo Moratalla, Caparrós, Madrid, 1993, 57ss. Del propio Ricoeur es interesante consultar su historia de cuatro modelos de justicia (Aristóteles, Kant, Hegel y Rawls): «Historia de la idea de justicia. I. La justicia según Aristóteles", Archipiélago, 3 (1989), pp. 33-39, «Historia de la idea de justicia. 2. Kant: de la moral a la doctrina del derecho", Archipiélago, 4 (1990), pp. 124-131, «Historia de la idea de justicia. 3. Hegel y el derecho penal”, Archipiélago, 18-19 (1994), pp. 200-210, «John Rawls: teoría de la justicia”, Archipiélago, 23 (1995), pp. 106-122.

32 Rawls, J., Teoría de la justicia, trad. de M ${ }^{\mathrm{a}}$ D. González, FCE, México, 1979. Cf. asimismo «Justicia como imparcialidad: política, no metafísica», en C. Gómez (ed.), Doce textos fundamentales de la Ética del siglo XX, Alianza, Madrid, 2002 (hay reed. posteriores), pp. 187-229. Para la confrontación con Habermas, cf. HABERMAS, J., y RaWLs, J., Debate sobre el liberalismo político, introd. de F. Vallespín, trad. de G. Vilar, Paidós, Barcelona 1998. 
la ignorancia, análogo del «estado de naturaleza» de las teorías contractualistas clásicas, nadie sabe el lugar que puede ocupar en una sociedad, en la que se supone que habrá ciertas desigualdades y se trata de favorecer (o de no hacer insoportable) la posición de los más desfavorecidos, que es la que a cada cual le puede corresponder. Con lo que la sospecha que recae sobre el sentido calculador de la regla de oro cuando se la mira desde la interpretación de la sobreabundancia resuena de nuevo aquí.

Los dos sentidos, el más utilitarista y el más desprendido o generoso, se superponen en los pasajes evangélicos, que después de recomendar la regla de oro, prosiguen: "Mas si amáis a quienes os aman, ¿qué merito tenéis? También el hombre pecador lo hace. Si prestáis a aquellos de quienes esperáis recibir, ¿qué mérito hay en ello? (Lc 6, 32-34). Por eso, enuncian lo que a Freud le parecía escandaloso: "Amad a vuestros enemigos y haced bien a quienes os ofendan. Y a quienes os pidan la capa, dadle también el manto" (Lc. 6, 27-30)».

Esta última inspiración es la que puede llevar a compromisos extremos, como los han podido realizar Gandhi o Martin Luther King. Pero, como vimos que sucedía en la tensión entre amor e imperativo, de nuevo aquí es preciso tener en cuenta que la «orden» de amar no abole la regla de oro, sino que la reinterpreta en el sentido de la generosidad, pues, según indicamos, lo supramoral no ha de anular lo moral, sino, asumirlo para rebasarlo. Por ello, si el amor no debía conculcar el deber, tampoco ahora la lógica de la sobreabundancia debe pasar por alto el principio de moralidad resumido en la regla de oro y formalizado en el principio de justicia, a fin de que el supuesto amor no sea un simple capricho o extravío. Lo que, no obstante, la interpretación desde la lógica de la sobreabundancia aporta es resguardar a la lógica de la equivalencia de caer en sus interpretaciones perversas y meramente calculadoras.

Susceptible de dos lecturas, la una interesada, la otra desinteresada, sólo el mandamiento del amor puede decidir en favor de la segunda frente a la primera. Y de manera similar a como la Regla de Oro, dejada a sí misma, se rebaja al rango de máxima utilitaria, la regla de justicia, dejada a sí misma, tiende a subordinar la cooperación a la competencia, o incluso a esperar del solo equilibrio de los intereses rivales el simulacro de la cooperación ${ }^{33}$.

Es quizá todo ello lo que llevaba a Habermas, pese a su declarado agnosticismo, a indicar:

«Mientras el lenguaje religioso siga llevando consigo contenidos semánticos inspiradores, contenidos semánticos que resultan irrenunciables, pero

33 En relación con estas cuestiones es de interés consultar: THIEBAut, C, «El perdón, la reconciliación y la justicia», en M. Giusti, G. Gutiérrez, E. SALmón (eds.), La verdad nos hace libres, Fondo editorial de la Pontifica Universidad Católica del Perú, Lima, 2015, pp. 73-95. Perspectivas para una justicia global son abordadas por Velasco, J. C., «La justicia en un mundo globalizado», Isegoría , 43 (2010), pp. 349-362 (La sección monográfica de ese número de la revista está dedicada al tema de la justicia global). 
que se sustraen (¿por el momento?) a la capacidad de expresión del lenguaje filosófico y que aguardan aún a quedar traducidos al medio de la argumentación racional, la filosofía, incluso en su forma posmetafísica, no podrá ni sustituir ni eliminar a la religión $»^{34}$.

Y, aún más explícitamente, a resaltar, en la tensión secular entre pensamiento filosófico de raíz griega y cristianismo, las aportaciones de doble dirección entre ambos, situando entre las que el cristianismo ha hecho valer ante la reflexión filosófica el imperativo de igual respeto por todos, incluidos especialmente los ajenos y extraños:

«Sin esta infiltración del pensamiento de origen genuinamente judaico y cristiano en la metafísica griega no hubiéramos podido constituir aquel entramado de conceptos específicamente modernos que convergen en un concepto de razón a la vez comunicativa e históricamente situada. Pienso en el concepto de libertad subjetiva y en el imperativo de igual respeto para todos, incluso y precisamente para el que resulta extraño en virtud de su particularidad y su carácter diferenciado [...]. A ello hay que añadir también la conciencia de falibilidad de la mente humana, de la contingencia de las condiciones bajo las cuales ésta, con todo, sigue formulando pretensiones incondicionadas $»^{35}$.

Desde una perspectiva diferente, pero en un sentido similar, mas acentuando la vinculación de la teoría de la justicia con la religión, ya José Luis L. Aranguren señaló en su día cómo las teorías contractualistas de la justicia necesitaban una fuerza de motivación religiosa desde la que poder abordar la cuestión de la solidaridad. En diálogo con Javier Mugerza, señalaba Aranguren:

«Estoy al cabo de la calle de que la nietzscheana “muerte de Dios" es hoy una realidad irreversible para muchísima gente, que no por ello está dispuesta a renunciar a la ética, pero para mí personalmente, en tanto que creyente, Dios no ha muerto o, si usted quiere, creo no haber perdido totalmente la sensibilidad para el "misterio", y hay capítulos de la ética que no sabría cómo abordar si de algún modo no lo hago "desde la religión". Por ejemplo, no tendría nada que objetar al tratamiento contractual o cuasi contractual del problema de la justicia por parte de la "ética comunicativa” contemporánea o corrientes afines, pero no veo claro, en cambio, cómo cabría abordar desde esos planteamientos un problema como el de la

34 Habermas, J., Pensamiento postmetafísico, trad. de M. Jiménez Redondo, Taurus, Madrid, 1990, pp. 62-63.

35 Habermas, J., «Israel o Atenas: ¿a quién pertenece la razón anamnética?», en Fragmentos filosófico-teológicos, trad. de J. C. Velasco, Trotta, Madrid, pp. 89-100, cit. pp. 93-94. Con posterioridad, HaBERmas ha abordado las condiciones de diálogo entre sociedad secular y tradiciones religiosas en Entre naturalismo y religión, trad. de P. Fabra Abat, Paidós, Barcelona, 2006, y también en Mundo de la vida, política y religión, trad. de J. Seca, Trotta, Madrid, 2015. Un buen estudio sobre las posiciones de Habermas al respecto en DíAz-SALAZAR, R., Democracia laica y religión pública, Taurus, Madrid, 2006. Realicé un comentario sobre esta obra en Gómez, C., «Laicismo y presencia pública de la religión», Isegoría, 40 (2009), pp. 305-308. 
solidaridad, cuya instauración no necesita ni muchas veces puede descansar en un contrato social concertado en condiciones de simetría entre las partes y que para mí es heredera de la fraternidad cristiana y, por ende, remite a la religión ${ }^{36}$.

Y el propio Javier Muguerza, desde una orientación agnóstica, ha reconocido algo similar cuando, al recordar la fórmula de Bonhoeffer, según la cual "hemos de vivir en el mundo etsi Deus non daretur», como si Dios no existiera ( $\mathrm{Y}$ esto es precisamente lo que reconocemos...jante Dios! [...]. ¡Ante Dios y con Dios vivimos sin Dios!» ${ }^{37}$ ), la recogía, invirtiéndola, para proponer vivir la solidaridad humana ut si Deus daretur, como si Dios existiera, pues, a su entender:

«La solidaridad acaso vaya más allá de la simple virtud ética de la justicia y necesite de una fuerza de motivación religiosa, que nos haga vivir nuestra común humanidad como una comunión y no sólo como comunidad y a la que el individuo, desde la soledad de su conciencia y aun sumido en la insuperable incertidumbre que deriva de su increencia, responda con su acción como si hubiera Dios, ut si Deus daretur» ${ }^{38}$.

Y es que, para retornar de este modo al núcleo central de nuestra cuestión, podríamos decir que la «supramoralidad» del mandamiento del amor no equivale sin más a una simple suspensión de la ética, sino a su rebasamiento, recogiéndola. Pues, para no extraviarse en la fantasía o en la simple inmoralidad, el amor debe estar referido al principio de justicia, el cual, por otra parte, sólo es reorientado a través de la continuación y la rectificación de la regla de justicia en sentido opuesto a su inclinación utilitaria. De este modo, y para decirlo ahora con Ricoeur, «la sobreabundancia se convierte en la verdad oculta de la equivalencia. La regla es "repetida”. Pero la "repetición” significa transfiguración» ${ }^{39}$.

Así vemos cómo las tensiones observadas anteriormente entre amor e imperativo se pueden hacer extensivas a las relaciones entre amor y justicia. En ambos casos, el amor «supera» al imperativo o a la justicia. Pero necesita referirse a ellos si es que no quiere perderse en cualquier falso sentimentalismo que conculca lo que dice superar. La tensión entre imperativo moral, regla de justicia y amor debe ser mantenida para preservar a aquéllos de su sequedad o sus interpretaciones perversas y a

36 Muguerza, J., «Del aprendizaje al magisterio de la insumisión. (Conversación con José Luis L. Aranguren)», en Gómez, C., José Luis L. Aranguren. Filosofía y vida intelectual, Trotta, Madrid, pp. 371-410, cit. pp. 407-408.

37 Bonhoeffer, D., Resistencia y sumisión, trad. de M. Faber-Kaiser, Ariel, Barcelona, 1971, pp. 209-210.

38 Muguerza, J., "La profesión de fe del increyente. Un esbozo de (anti)teodicea», en M. Fraijó y J. Masiá, eds., Cristianismo e ilustración. Homenaje al profesor José Gómez Caffarena en su setenta cumpleaños, Universidad Pontificia de Comillas, Madrid, 1995, pp. 185-213, cit. pp. 212-213.

39 Ricoeur, P., Amor y justicia, cit., p. 65. 
éste de su extravío pseudomístico o francamente inmoral, que lo traiciona allí mismo donde cree realizarlo ${ }^{40}$.

\section{EL AMOR A LOS «FUERA DE LA LEY»}

Y ya que en la última nota acabamos de aludir a la literatura, es preciso señalar que, además de en algunos de los ejemplos históricos a los que hemos hecho referencia, la lógica de la sobreabundancia de la que hablamos se pone asimismo de relieve en determinados testimonios literarios, que, acercándose a los históricos, tratan de plantear la cuestión no tanto conceptualmente, o in effigie, sino, por así decirlo, in vivo ${ }^{41}$. Ente otros que se podrían considerar, aquí nos detendremos brevemente para terminar en ciertos pasajes de la obra de Dostoievski, que, como veremos, no se encuentran lejos de lo que Pablo manifestaba, no ya en el famoso himno al amor de 1 Cor 13, tantas veces recordado y sobre el que ha vuelto con insistencia, por ejemplo, Gianni Vattimo en nuestros días, en su lectura, un tanto unilateral a mi modo de ver, del cristianismo ${ }^{42}$, sino más bien en 1 Cor 1 , al que con posterioridad aludiremos.

Dostoievski puede representar bien, precisamente, uno de los modelos de ese cristianismo trágico que Vattimo desdeña (y en cuyo phylum se situarían figuras tan eminentes para lo que el cristianismo ha sido como Lutero, Pascal y su «Dios oculto» o Kierkegaard), pero sin el cual se amputarían gravemente algunas de sus mayores realizaciones. Sin detenernos en los problemas de conjunto de la visión religiosa de Dostoievski ${ }^{43}$, queremos hacer hincapié en

40 Ya diversos teólogos y moralistas, por ejemplo Pascal, advirtieron de que no hay nada más parecido al deseo de incorporarlo todo a sí mismo, que el amor, ahí incluido el supuesto amor a Dios. Esa crítica del pseudomisticismo también se ha hecho magistralmente en la literatura. Por poner un solo ejemplo, pero un ejemplo mayor, podemos recordar la sucinta, mas eficaz, ironía con la que Flaubert describe las ansias divinas de Emma Bovary, cuando, desengañada de su marido, su trabajo, sus lecturas, su piano, sus aficiones y sus amantes, cree descubrir un día "otra felicidad mayor; un amor por encima de todos los amores, sin intermitencia ni fin [...]. Quiso ser una santa. Se compró un rosario, se puso amuletos [...]. Cuando se arrodillaba en su reclinatorio gótico, le murmuraba a Dios las mismas palabras de dulzura que a sus amantes, en los desahogos del adulterio» (Flaubert, G., Madame Bovary, trad. de G. Palacios, Cátedra, Madrid, $5^{\mathrm{a}}$ ed., 1993, pp. 281-282).

41 De las relaciones entre literatura y vida me he ocupado en Gómez, C., «La vida como narración», Daimon, 68 (2016), pp. 67-83.

42 Vattimo, G., Creer que se cree, trad. de C. Revilla, Paidós, Barcelona, 1996. (Un comentario a esa obra lo realicé en GómEz, C., "La caridad y el absurdo», Iglesia viva, 192 (1997), pp. 188-193). Del propio Vatтimo puede consultarse también su Después de la cristiandad, trad. de C. Revilla, Paidós, Barcelona, 2004. (Un breve comentario en Trías, E., "Después de la Cristiandad», El Mundo, 01/04/2004).

${ }_{43}$ Sobre la cuestión sigue teniendo interés el estudio de Aranguren, J. L. L., El cristianismo de Dostoievski, Taurus, Madrid, 1970. Desde el ámbito de la teología protestante, quizá el intento de respuesta más interesante al que denomina "ateísmo de protesta» de algunos de los personajes de Dostoievski, lo llevó a cabo Moltmann, J., El Dios crucificado. 
la esperanza en el amor, en este caso el amor de Dios o el Dios-Amor, que, frente a todos los que creen poder justificarse por sí mismos, llama también a todos los perdidos y fracasados, a los «humillados y ofendidos», indigentes, mendigos y descarriados, con los que ni siquiera puede hacerse una revolución, pues están entregados a la nada; ese lumpen sobre el que Marx tan duras palabras pronunció, dado que, según él, dependían más que otros de las clases dominantes para su supervivencia y carecían de conciencia de clase. Tal como él mismo lo describió en El 18 Brumario de Luis Bonaparte, en él se encuentran:

«Junto a roués arruinados, con equívocos medios de vida y de equívoca procedencia, junto a vástagos degenerados y aventureros de la burguesía, vagabundos, licenciados de tropa, licenciados de presidio, huidos de galeras, timadores, saltimbanquis, lazzaroni, carteristas y rateros, jugadores, alcahuetes, dueños de burdeles, mozos de cuerda, escritorzuelos, organilleros, traperos, afiladores, caldereros, mendigos; en una palabra, toda esa masa informe, difusa y errante» ${ }^{44}$.

Pues bien, uno de esos personajes es precisamente Marmeladov, de Crimen y castigo, al que sucintamente me quiero ahora referir. Ya en el núcleo argumental de la novela se sitúa esa preferencia por los desarrapados, pues no podemos olvidar que el asesino, Raskolnikov, no es convertido por miembros del clero, doctos ni letrados, sino por una mujer de la calle, Sonia, la prostituta, la hija de Marmeladov, leyéndole un pasaje sobre la resurrección de Lázaro, pues si éste resucitó, aunque ya hedía, también Raskolnikov puede resucitar a una nueva vida, pese a que su comportamiento hieda ${ }^{45}$. Mas, antes de ese pasaje central, enseguida, y nada más se abre la novela, tras el ensayo del crimen en el capítulo primero, en el segundo Raskolnikov se encuentra en una taberna con Marmeladov, antiguo funcionario arruinado y borracho, que está desvariando, lo que da pie a uno de los pasajes más hermosos de la obra («la belleza como símbolo de la moralidad ${ }^{46}$ ). Relatando parte de sus desgracias, Marmeladov se refiere a cuando su única hija fue por primera vez a la policía para inscribirse y que le dieran la tarjeta amarilla, que la señalaba como prostituta, y él la acompañó, pese a las risas que semejantes confesiones despertaban en dos

La cruz de Cristo como base y crítica de toda teología cristiana, trad. de S. Talavero, Sígueme, Salamanca, 1975. Es asimismo de sumo interés la lectura propuesta por KolaKowsKi, L., Si Dios no existe..., trad. de M. Sansigre, Tecnos, Madrid, 1985, de la que me he ocupado en diversas ocasiones: Gómez, C., «Kolakowski y la religión: reflexiones sobre un tema de Dostoievski», Pensamiento, vol. 46 (1990), pp. 201-224; «Ética y religión», en C. Gómez y J. Muguerza (eds.), La aventura de la moralidad. Paradigmas, fronteras y problemas de la Ética, Alianza, Madrid, 2007, pp. 278-329; «Religión, política y metafísica en Leszek Kolakowski», en J. San Martín y J. J. SÁnchez (eds.), Pensando la religión. Homenaje a Manuel Fraijó, Trotta, Madrid, 2013, pp.312-324.

44 Marx, K., El 18 Brumario de Luis Bonaparte, Fundación Federico Engels, Madrid, 2003, pp. 63-64.

45 Dostoievski, F., Crimen y castigo, $3^{\text {a }}$ parte, cap. V

46 Kant, I., Crítica del Juicio, trad. de M. García Morente, Espasa-Calpe, Madrid, $2^{\text {a }}$ ed., 1981, parágrafo 59, p. 260. 
muchachos que se encontraban en la taberna y en el propio tabernero. Y cómo su nueva mujer, Catalina Ivanovna, una persona bien educada pero venida a menos, la animó entre los llantos de sus criaturas y en medio de sus dolencias a que fuera a hacer la calle, pese a que todavía era una niña tímida, de voz dulce, delgada, de carita pálida. Al principio se negó, con las consiguientes burlas de la madrastra — «Yo no puedo hacer eso, repitió, remedándola, Catalina Ivanovna. ¡Vaya un tesoro, para que lo guardes con tanto cuidado!»—, pero él mismo, aunque estaba tendido borracho en un jergón, vio cómo:

«Cerca de las cinco de la tarde, Sonetchka se levantaba, se ponía un pañuelo en la cabeza, cogía un chal y salía de la habitación. Eran más de las ocho cuando regresó: Entró, se fue derecha a Catalina Ivanovna y, sin desplegar los labios, depositó ante ella, en la mesa, treinta rublos. No pronunció ni una palabra, no miró a nadie; se limitó a cubrirse la cabeza y la cara con un chal de paño verde y a echarse en la cama, de cara a la pared. Leves estremecimientos recorrían sus frágiles hombros y todo su cuerpo... Y yo seguía acostado, ebrio todavía. De pronto vi que Catalina Ivanovna, también en silencio, se acercaba a la cama de Sontetchka. Le besó los pies, los abrazó y así pasó toda la noche, sin querer levantarse. Y al fin se durmieron las dos juntas, enlazadas... ${ }^{47}$

Y Marmeladov explica que por eso bebe, para sentir más, para sufrir más (Freud llamó la atención en varias ocasiones sobre el carácter masoquista de muchos personajes de la literatura $\mathrm{rusa}^{48}$ ), aunque reconoce que no merece compasión. Mas, pese a todo, no pierde la esperanza en aquel que mostrará piedad por todos los hombres:

«No merezco que nadie me compadezca; lo que merezco es que me crucifiquen. ¡Sí, la cruz, no la compasión...! Yo mismo me encaminé al suplicio, pues tengo sed de dolor y de lágrimas, no de alegría. ¿Crees acaso, comerciante, que la media botella me ha proporcionado algún placer? Sólo dolor, dolor y lágrimas he buscado en el fondo de este frasco... Sí, dolor y lágrimas... Y los he encontrado, y los he saboreado. Nosotros no podemos recibir la piedad sino de Aquel que ha sido piadoso con todos los hombres; de Aquel que todo lo comprende, del único, de nuestro único Juez. Él vendrá el día del Juicio y preguntará: “¿Dónde está esa joven que se ha sacrificado por una madrastra tísica y cruel y por unos niños que no son sus hermanos? ¿Dónde está esa joven que ha tenido piedad de su padre y no ha vuelto la cara con horror ante ese bebedor despreciable?" Y dirá a Sonia: "Ven, yo te perdoné..., te perdoné... y ahora te redimo de todos tus pecados, porque tú has amado mucho". Sí, él perdonará a mi Sonia. Él la perdonará, yo sé que Él la perdonará. Todos seremos juzgados por Él, los buenos y los malos. Y nosotros oiremos también su palabra. Él nos dirá: "Acercaos, acercaos, también vosotros los

47 Dostoievski, F., Crimen y castigo, ed. electrónica http://www.LibrosElectronicosGratis. $\mathrm{com} /, 1^{\mathrm{a}}$ parte, cap. II, pp. 14-15. Puede consultarse también, en traducción de I. Vicente, en Anaya, Madrid, 1991.

48 Cf., por ejemplo, Freud, S., El problema económico del masoquismo, en $O$. C., cit., T.III, pp. 2752-2759. Sobre Dostoievski publicaría más tarde Dostoievski y el parricidio, en $O$. C., cit., T. III, pp. 3304-3016 
bebedores; acercaos, débiles y desvergonzadas criaturas”. Y todos avanzaremos sin temor y nos detendremos ante Él. Y Él dirá: “¡Os habéis comportado como cerdos y sois como bestias. Pero venid conmigo también!”. Entonces, los inteligentes, los sabios, los prudentes y los austeros se volverán hacia Él y exclamarán: “Señor, ¿por qué recibes a éstos?” Y Él responderá: “Los recibo, ¡oh sabios!, los recibo, ¡oh personas sensatas!, porque ninguno se ha considerado jamás digno de ello". Y Él nos tenderá sus divinos brazos y nosotros nos arrojaremos en ellos, deshechos en lágrimas... y lo comprenderemos todo, entonces lo comprenderemos todo... y todos comprenderán... ${ }^{49}$.

Y es quizá esa no autosatisfacción la que acerca, como decíamos, el texto al pasaje de 1 Cor 1 , al que antes me refería, en el que Pablo trata de hablar de una imagen de Dios que contradice a la de los judíos, que buscan milagros, un mesías que les salvara del poder romano, y la de los griegos que buscan sabiduría, esto es, demostrar a Dios mismo. Con lo cual, como bien vio entre nosotros José $\mathrm{Gaos}^{50}$, se hacen superiores a Él, que es quizá por lo que los pasajes de Rom 1 que aluden al posible conocimiento de Dios por sus obras ( «porque lo invisible de Dios, desde la creación del mundo, se deja ver a la inteligencia a través de sus obras», Rom 1, 20; conocimiento que no tendría por qué equivaler a una «demostración» en el sentido actual del término) han de ponerse dialécticamente en relación, como Moltmann entre otros señaló en su día, con los ahora comentados, si es que tal posible conocimiento no quiere envanecerse al margen de la manifestación de Dios en la impotencia de la cruz. Y enseguida Pablo saca las consecuencias sociales y políticas de tal concepción, en la preferencia de Dios por los pobres frente a los ricos, por los débiles frente a los poderosos, por los necios para confundir a los que se jactan de su saber. E incluso, radicalizando y universalizando el discurso, lo que permitiría acoger a cada cual en su propia nadería, "por lo despreciable del mundo y lo que no es, para reducir a la nada lo que es, a fin de que ningún mortal se gloríe en la presencia de Dios. Y el que se gloríe, que se gloríe en el Señor», que, como indica más adelante «será todo para todos» (1 Cor 15,28).

Ese amor que se despliega no sólo hacia lo hermoso y bello, sino asimismo ante lo aparentemente despreciable y vulgar, e incluso lo éticamente reprobable, es capaz de alcanzar la nada que surca al ser humano, por mucho que cada cual trate de ocultárselo. Mas, precisamente por ello, es capaz de recuperar la dignidad que no necesita claudicar y agacharse, pero tampoco andar estirándose, sino que puede disponer a la andadura vertical y el paso erguido de los que hablaba Ernst Bloch, más allá de los sentimientos de desprecio y de las fantasías de poder. Obviamente, es un amor que supera las relaciones exigibles

\footnotetext{
49 Dostoievski, F., Crimen y castigo, cit., $1^{\text {a }}$ parte, cap. II, p. 18.

50 Gaos, J. y Larroyo, F., Dos ideas de la Filosofía, ed. digital de la Biblioteca virtual Miguel de Cervantes basada en la edición de La Casa de España en México, en: www. cervantesvirtual.com/bib/extras_autor/00002616/hipertextos/word/gaosfdf.rtf
} 
en la lógica de la reciprocidad y se inscribe en la lógica de la sobreabundancia, de las que antes hablamos. Un amor que no por ello exime de la crítica, pero que, sin conculcar los imperativos éticos o de justicia, es capaz de ir más allá de ellos, para rescatar y proveer de dignidad a todo lo aparentemente despreciable y a la nada que nos atraviesa.

Y para concluir enlazando con el comienzo, retomado ahora a otro nivel, podemos recuperar las tempranas alusiones que hicimos a Ortega. Obviamente, Ortega está muy lejos del temple apocalíptico y atormentado de Dostoievski, tanto como en buena medida lo está de las formulaciones y la concepción de Pablo ${ }^{51}$. Pero también el animoso Ortega supo indicar en alguna ocasión que cuando un hombre se ve como realmente es, se ve como "un pobre hombre ${ }^{52}$. Y tal vez por ello, el Ortega inicial y más esperanzado no quería sobrevolar por encima del mundo sino asirle también en sus aspectos aparentemente más ínfimos para llevarlos a su plenitud, que es, como tuvimos ocasión de señalar, su concepción del amor en Meditaciones del Quijote, lo que denominaba «salvaciones» ${ }^{53}$.

«Es frecuente en los cuadros de Rembrandt que un humilde lienzo blanco o gris, un grosero utensilio de menaje se halle envuelto en una atmósfera lumínica e irradiante, que otros pintores vierten sólo en torno a las testas de los santos. Y es como si nos dijera en delicada amonestación: ¡Santificadas sean las cosas! ¡Amadlas, amadlas! Cada cosa es un hada que reviste de miseria y vulgaridad sus tesoros interiores ${ }^{54}$.

Es en función de ello por lo que alaba la actitud que no sólo va en pos de lo canonizado y bello, sino que es capaz de reparar en lo aparentemente despreciable y vulgar, no para condenarlo en su aparente estado, sino para saber ver, más allá de él, la plenitud posible oculta tras él.

Facultad de Filosofía, UNED

cgomez@fsof.uned.es

Carlos Gómez SÁNCHez

[Artículo aprobado para publicación en enero de 2018]

51 A los pasajes de 1 Cor 1 de Pablo se refiere precisamente Ortega en «En el tránsito del Cristianismo al racionalismo" y en "Sobre el extremismo como forma de vida», en En torno a Galieleo, en O. C., T. V, pp. 13-165, cit. pp. 93ss.

52 Ortega y Gasset, J., Prólogo a "Historia de la Filosofía de Émile Bréhier» (Ideas para una Historia de la Filosofía), en O. C., cit., T. VI, pp. 377-418. La observación figura incluso a propósito de los clásicos, a fin de combatir la que considera beatería clasicista: «La beatería no es culto ni entusiasmo, sino la forma indiscreta de ambos. Peralta al "clásico" sobre el nivel de la historia y en vez de intentar derechamente entenderlo como lo que es - como un hombre entre los hombres, y esto quiere decir un "pobre hombre»- parte en su ocupación con él resuelto a admirar, anticipando en su obra perfecciones imaginarias a las que, quiérase o no, adapta los textos» (p. 383).

53 Como él mismo advierte, «la "salvación" no equivale a loa ni ditirambo; puede haber en ella fuertes censuras. Lo importante es que el tema sea puesto en relación inmediata con las corrientes elementales del espíritu, con los motivos clásicos de la humana preocupación» (Ortega y Gasset, Meditaciones del Quijote, en O. C., cit., T. I, p. 312).

$54 \quad$ Ibid. 